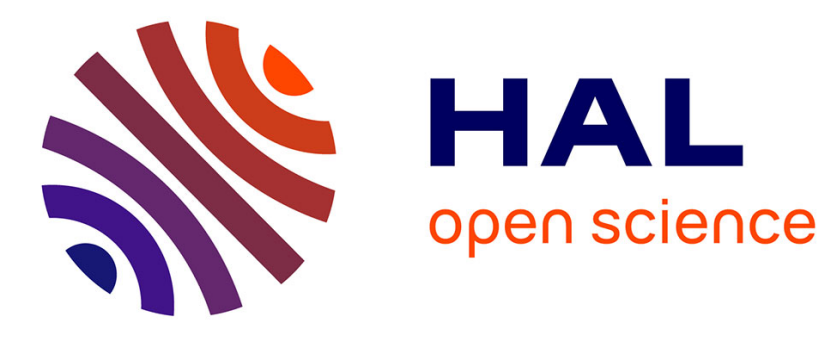

\title{
Mining economist opinions on using multi-agent methodology to simulate metal markets
}

Gaétan Lefebvre, Fenintsoa Andriamasinoro

\section{To cite this version:}

Gaétan Lefebvre, Fenintsoa Andriamasinoro. Mining economist opinions on using multi-agent methodology to simulate metal markets. SIBR 2015 Bangkok Conference on Interdisciplinary Business \& Economics Research, Society of Interdisciplinary Business Research, Jun 2015, Bangkok, Thailand. 10.1504/IJTGM.2016.074139 . hal-01144050

\section{HAL Id: hal-01144050 https://hal-brgm.archives-ouvertes.fr/hal-01144050}

Submitted on 20 Apr 2015

HAL is a multi-disciplinary open access archive for the deposit and dissemination of scientific research documents, whether they are published or not. The documents may come from teaching and research institutions in France or abroad, or from public or private research centers.
L'archive ouverte pluridisciplinaire HAL, est destinée au dépôt et à la diffusion de documents scientifiques de niveau recherche, publiés ou non, émanant des établissements d'enseignement et de recherche français ou étrangers, des laboratoires publics ou privés. 


\title{
Mining economist opinions on using multi-agent methodology to simulate metal markets
}

\author{
Gaétan Lefebvre \\ BRGM - GeoResources Directorate, 3 avenue Claude Guillemin, Orléans, France \\ g.lefebvre@brgm.fr \\ Fenintsoa Andriamasinoro* \\ BRGM - GeoResources Directorate, 3 avenue Claude Guillemin, Orléans, France \\ f.andriamasinoro@brgm.fr
}

(Corresponding Author indicated by an asterisk *)

Presented at the: SIBR 2015 Conference on Interdisciplinary

Business and Economics Research, 4-6 June 2015, Bangkok.

\begin{abstract}
In coming years, mining economists expect the international demand for metals to rise. Market distortions are likely to appear, because producing countries controlling the resources can implement exportation quotas for certain categories of metals. Consequently, consuming countries like France face increasing risks of shortages of some metals. In response, the French government suggests that a set of prospective tools be implemented, including a prospective simulation tool based on a multi-agent system approach. The goal of this paper is to report and discuss critiques by mining economists on the value and abilities of multi-agent systems (MAS) to simulate critical metal markets whenever the approach is appropriate. The critiques are collected by confronting an existing agent-based computational economics (ACE) model of the lithium market with market reality and then by applying the discussions generally to other metals. The motivation is (a) to define the gaps currently existing between MAS and mining (b) to provide indicators on how the ACE model should be enhanced to reduce these gaps and (c) to produce an improved initial metal classification that is suitable for such a modelling exercise.
\end{abstract}

Keywords: metal markets, agent-based models, prospective simulation

\section{INTRODUCTION}

In coming years, the growing demand for industrialization processes and progress in technologies means that mining economists will expect the international demand for metals to rise. At the same time, the world market for metals is becoming more and more complex, involving a great variety of players and mechanisms radically different from past decades. For instance, the concept of "critical metals" (Graedel et al., 2012) has arisen. Here two situations meet. On one hand, some consuming countries (such as France) and their manufacturing industries depend on importing a certain category of metals (antimony, rare earths, lithium, etc.) necessary for new technologies but unavailable in these countries. On the other hand, producing countries can destabilize the market thanks to their dominant position, by implementing exportation quotas for instance. Consequently, the consuming countries are at risk of shortage. To deal with these situations, the French government is suggesting the implementation of a set of prospective tools. This would allow the government to answer the following question: Given supply uncertainty, how long would a metal supply shortage last (should the 
case arise) in the world market and in France? One element of this set, which we suggest here, is a prospective simulation tool based on a multi-agent system (MAS) approach. More specifically, the tool contains agent-based computational economics (ACE) models i.e. models of artificial markets that are populated by economic interacting agents (Tesfatsion, 2006).

The goal of this paper is to report and discuss critiques by mining economists regarding an existing ACE model (see Section 2.2) that simulated the world lithium market. The motivation behind collecting these critiques is that these economists will be more willing to accept the ACE approach for the simulation of metal markets whenever the approach is appropriate. The critiques are collected by confronting the model (called "reference model" in this paper) with market reality and beyond the unique case of lithium. The reference model was implemented by MAS modelers with a view to long-term development of methodologies for metal market forecasts but mining economists need short-term operational tools and are not fully familiar with MAS. This paper does not present an alternative model (i.e. a 'better' tested and validated model than the reference model) stemming from these critiques, or plan to improve any agent architecture. This is a more theoretical discussion that aims (a) to define the gaps currently existing between MAS and mining economists (b) to indicate how the ACE model should be enhanced in the future to reduce these gaps and (c) in parallel, to produce an improved initial metal classification that is suitable for such a modelling exercise.

Section 2 of this paper presents the state of the art for metal market modelling and includes a reminder on the reference model that we discuss throughout the paper. Section 3 presents the critiques of the model from the mining economists as is. Section 4 presents the responses to these critiques by the MAS modelers and suggests possible changes in the model, based on these critiques. Section 5 concludes the paper.

\section{State OF THE ART}

\subsection{Preamble: The general structure of metal markets}

\subsubsection{Classification of metals}

On international markets, metals are usually divided into four categories: base metals, ferrous metals, precious metals and minor metals (Table 2.1).

\begin{tabular}{|c|c|c|}
\hline Category & Chemical & Trading platform \\
\hline Base metals & Aluminum, copper, lead, zinc, tin, nickel & \multirow{3}{*}{$\begin{array}{l}\text { London Metal Ex- } \\
\text { change (LME) and } \\
\text { Shanghai Futures Ex- } \\
\text { change (SHFE) }\end{array}$} \\
\hline Ferrous metals & $\begin{array}{l}\text { Iron ore, chromium, manganese, molyb- } \\
\text { denum, niobium, vanadium }\end{array}$ & \\
\hline Precious metals & Gold, silver, platinum, palladium & \\
\hline Minor metals & $\begin{array}{l}\text { Antimony, beryllium, bismuth, cobalt, gal- } \\
\text { lium, germanium, hafnium, indium, lithi- } \\
\text { um, rare earths, rhenium, selenium, tanta- } \\
\text { lum, tellurium, tungsten, zirconium }\end{array}$ & $\begin{array}{l}\text { FANYA Metal Ex- } \\
\text { change (at a starting } \\
\text { stage) }\end{array}$ \\
\hline
\end{tabular}

Table 2.1: Metal categories and trading platforms

LME and SHFE introduced in Table 2.1 are the main references for the market to obtain the global reference of prices for base, ferrous and precious metals. By contrast, 
for the minor metals, no complete trading platform exists for their markets. In fact, the FANYA Metal Exchange, created in China in 2011, should gradually play this role in the future, but it cannot pretend to be a centralized market place yet. In most cases, trading for this category of metals is done directly between the seller (producer) and the buyer (final industrial manufacturer), without any supervisory authority (an "Over the Counter" exchange).

\subsubsection{Metal markets}

Metal markets should not be compared with other commodity markets. The logistics of the process of mining metallic deposits are very different from the logistics of exploiting commodities like oil and gas deposits, or of growing crops: the geological nature of metallic deposits (where one deposit can contain many metals) leads to a particular model of industrial development (the metal having higher price will be more exploited from this deposit) and thus, specific impacts on the availability of metal-based products on international markets ${ }^{\underline{1}}$. Generally, the following steps take place in the production process of metals: (a) extraction, where various metals can be obtained, some being by-products of others as a function of their prices (b) metallurgy treatment, i.e. all the processes from separating the mineral of interest to obtaining a tradable chemical product (oxide, ingot, powder), (c) transformation into pieces usable by the manufacturing industries, (d) distribution to these manufacturers and (e) distribution of the final metal-containing goods (e.g. cars having batteries containing lithium, lead, etc.) to consumers.

\subsection{Summary on the MAS reference model}

The ACE reference model (Andriamasinoro \& Martel-Jantin, 2013) discussed in this paper simulated a lithium market. The product was lithium carbonate $\left(\mathrm{Li}_{2} \mathrm{CO}_{3}\right)$, an important element in the manufacture of end-use batteries. The model then excluded other products like lithium hydroxide $(\mathrm{LiOH})$ or lithium chloride $(\mathrm{LiCl})$.

Model design was motivated by the fact that whereas MAS generates increasing interest in the social or economic modeling of many types of market commodities (such as agricultural commodities (Torii et al., 2006), fishing commodities (Soulié \& Thébaud, 2006) or energy commodities (Van Pruissen et al., 2014)) the world of geosciences has shown very little interest in MAS to model mining metal commodities. Geoscience, and especially models dealing with supply shortages, has adopted only the global scale as the level of their studies. Furthermore, to determine probable rupture periods at that level, production and consumption have been estimated in an independent manner and the results then compared arithmetically. The prospective studies are based on a simple extrapolation of current market trends. Consequently, there is no reciprocal balancing between supply and demand (absence of a systemic approach). Figure 2.1 illustrates this situation for lithium and rare earths respectively.

$\underline{1}$ Such heterogeneity exists less in other commodities. 

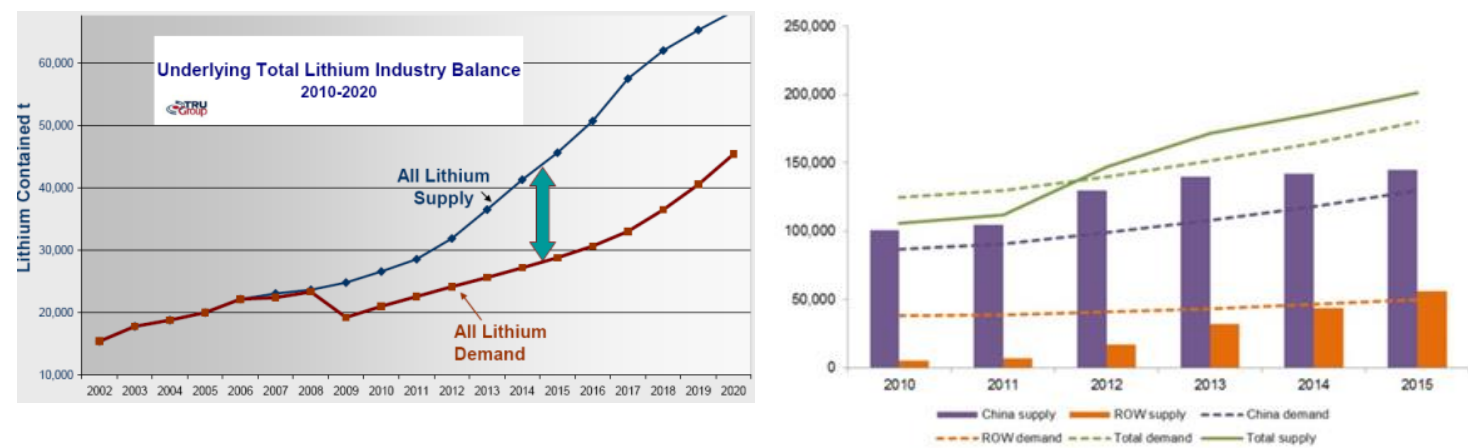

Figure 2.1: Prospective evolution of the lithium market till 2020 (left) (Tru, 2011) and the rare earth market till 2015 (right) (Roskill, 2011)

However, efforts to explore the criticality of metals should not consider only the global level, because organizational differences make a uniform analytical approach for all organizational levels (i.e., global, national and local) impractical (Graedel et al., 2012). In addition, the risks of distribution may be underappreciated when discussing resources at a pure global level (Kushnir \& Sandén, 2012) because metal resources are distributed unevenly among countries. These arguments emphasize what (Labys, 2003) already concluded a decade ago regarding modeling commodity markets (including metals) and models' roles in economic development: new frontiers of research should realize that commodity market behavior is intertwined with an international economic mechanism that includes globalization and expanded trade as well as interactions with developed and developing macroeconomics, including related financial institutions. This new vision would allow the government of a consuming country, especially in a restriction policy context, to better evaluate the impacts of the individual behavior and constraints from producers on supply shortage periods (if any) of this government's country.

For at least these reasons, an ACE model (the reference model in this paper, summarized below) was developed. Agent-based modeling was an adequate response because it does not rule out coordination failures, instability or crisis (Lengnick, 2013), a crisis, where in the metal market, an important supply shortage may be a future occurrence. The reference model is then, in the best of our knowledge, one of the pioneers in applying a MAS approach to supply shortage issues in metal markets.

These next subsection recalls the reference model. It will however only present the necessary elements to understand this paper. For a more detail about the formalism of that ACE model, we refer the reader to (Andriamasinoro \& Martel-Jantin, 2013).

\subsubsection{The data source}

The reference model used international trade data from (GTIS, 2012) as data sources. The GTIS data presents flows (quantity and price) between producing countries and transit countries as well as between transit countries and consuming countries. However, only the quantity parameter had been considered by the reference model.

The prospective period of the simulation began in 2013. The historic period was between 2005 and 2012, a period when the lithium data necessary for that work were available.

\subsubsection{Structure of the reference model}

A country was modelled as an agent, which is either a producer, a consumer, or a transit (i.e. a country connecting producers and consumers). For various reasons (ad- 
ministrative, geographical, etc.), a given consumer can be supplied by the same producer via several transits.

A country may be in the following context: Normal, Restriction, Compensation or Waiting. The model also integrated agents called ambassadors which are delegate agents that handle the flow exchanged between countries (one ambassador per country peer group).

\subsubsection{Behaviour of the reference model}

At the beginning of the simulation, each country is in a Normal context. A Normal context is the market context of a supply without restriction. A Restriction context is a context where a producer country imposes a quota restriction to a consuming country.

In a Normal context, the interaction between a consumer cck and a producer pci via a transit $t c j$, at each time step of the market simulation, occurs by following the four stages below, in which the first two points concern the demand stage and the last two points concern the supply stage:

1. Each consumer cck having a demand cck. $\sigma \mathrm{d}$ asks its ambassador $A(\mathrm{tcj} \leftrightarrow \mathrm{cck}$ ) (for each $j$ ) to calculate the quantity $d(t c j \leftarrow c c k)$ to ask for from pci (for each $i$ ), the supply of which will next transit via tcj. A demand over time was calculated via two steps: (a) interpolating the time series of the GTIS data related to the demands from cck to tcj between 2005 and 2013, in order to obtain a regression line which would describe and prolong that demand evolution, and (b) removing, from the resulting interpolation, the current available stock that $A(t c j \leftrightarrow c c k)$ already has.

2. When $t c j$ has received the demands $d(t c j \leftarrow c c k$ ) (for each $k$ ) it transfers them to the ambassador $\mathrm{A}(\mathrm{pci} \leftrightarrow \mathrm{tcj})$ (for each $i$ ). The ambassador then calculates, from these demands, the part $\mathrm{d}(\mathrm{pci} \leftarrow \mathrm{tcj})$ for which $p c i$ will have to respond. This part is here calculated as being a linear regression on the GTIS data between 2005 and 2013 corresponding to $\mathrm{d}(\mathrm{t} c j \leftarrow \mathrm{cck}$ ) (for all $\mathrm{k}$ )

3. When the demand arrives at pci, the latter, in response, calculates the total supply $s(\mathrm{pci} \rightarrow \mathrm{tcj})$ it will provide all consumers. In a normal context supply equals demand, whereas in a restriction context, pci imposes a rate restriction pci.pr (with $0 \leq$ pci.pr $\leq 1$ ). In any case, the supply is then sent by pci (for each $i$ ) to $t c j$ via the ambassador $\mathrm{A}(\mathrm{pci} \leftrightarrow \mathrm{tcj})$.

4. When tcj has received the supplies from pci, it calculates and transfers to cck its part, via the ambassador $A(t c j \leftrightarrow c c k)$ (for each $j$, the sum of which is $c c k . \sigma s)$. This part is calculated as being a linear regression on the GTIS data between 2005 and 2013 corresponding to $s(p c i \rightarrow t c j)$ (for all $i$ ).

At the end of each time step, the available instantaneous stock of cck is the difference between the initial demand $c c k . \sigma d$ and the final supply cck. $\sigma s$.

A Compensation context is a context where a producer country attempts to partly make up the lack resulting from that restriction by another country. In a compensation context, a consuming country receiving a restriction from pci (let $i=r$ ) changes its context from Normal to Compensation and asks all pci $(i \neq r)$ to make up the lacking stock. Each pci that receives the message and accepts to make up, either immediately switches its context from Normal to Compensation or waits for a delay. In the latter case, it first switches its context from Normal to Waiting before switching from Waiting to Compensation, once this delay expires. This delay may be necessary for diverse reasons specific to pci: inability to immediately respond, speculation, etc. 


\subsubsection{Simulation of the reference model and results}

The selected producing countries ( $\mathrm{pci}$ ) were Chile $(\mathrm{cl})$, China $(\mathrm{cn})$ and the United States (us). The model also added a (virtual) country called the rest of the world (rw). The selected consuming countries ( $\mathrm{cck}$ ) were France ( $\mathrm{fr}$ ), the subject of that study and, again, the rest of the world ( $\mathrm{rw})$. Finally, the transit countries $\left(\mathrm{tc}_{\mathrm{j}}\right)$ are Belgium (be), Germany (de), United Kingdom (uk), Italy (it) and the Netherlands (n1). The model also added, again, the rest of the world ( $\mathrm{rw}$ ). All the ambassadors were next naturally created to connect all these countries (rw included). To comply with the available data in GTIS, the simulation time step is 3 months. We note, for example, quarter 2 of year 2019 as 2/2019.

The pattern of the proposed (and currently fictitious) prospective scenario was the following: one assumes that as of 2014, Chile restricts its supply rate by cl.ps points. Following this situation, China accepts assuring compensation at a rate of cn.pp points, and does so immediately. The United States also accepts, with a rate of us.pp points, but only as of 2016. The purpose of the simulation then consisted in varying the values of these rates to find the shortage end date in France and in the rest of the world.

Table 2.2 shows in detail the list of different scenario instances proposed in this paper. An instance is made of the scenario identifier (written in brackets), the value of the restriction from Chile and the value of compensation, respectively from China and USA. The value chosen in this table also allows a policy maker to analyze the sensitivity of the lithium market after a variation in important indicators (e.g. here, the diverse rates).

\begin{tabular}{l|r|r|r}
\hline id & \multicolumn{1}{|c|}{$-\mathrm{cl} . \rho_{\mathrm{s}}$} & $+\mathrm{cn} . \rho_{\mathrm{p}}$ & \multicolumn{1}{c}{+ us. $\rho_{\mathrm{p}}$} \\
\hline (a) & -0.15 & +0.3 & +0 \\
(b) & -0.4 & +0.3 & +0 \\
(c) & -0.15 & +0.1 & +0 \\
(d) & -0.4 & +0.1 & +0.5 \\
(e) & -0.4 & +0.1 & +0.1 \\
(f) & -0.1 & +0.1 & +0 \\
\hline
\end{tabular}

Table 2.2: of All the Scenarios, an Instance Being Composed of a Restriction from Chile (cl) followed by a compensation from China (cn) and USA (us)

The left of Figure 2.2 next shows the shortage end dates obtained for the rest of the world in all scenarios. In this figure, the value of 13,000 (in t/quarter), in absolute values, approximately represents the average demand of lithium of $\mathrm{rw}$ (according to GTIS). It means for example that in scenario (f), at the peak time of a supply shortage period, there is still a minimal value of around $(13,000-5,800) \mathrm{t}$ /quarter of lithium (more than 50\%) which is supplied to this consumer.

The right of Figure 2.2 is the "France equivalent" of the left side, with an average demand of around $350 \mathrm{t}$ /quarter (according to GTIS). In this figure, France reaches a full shortage in all the scenarios where the Chile restriction is high $(-0.4)$, i.e. (b), (d), (e) and (f) and with different durations. The reason of this full shortage is that the linear regressions made on the GTIS data result to a behavior where the model first handles 
the rest of the world ( $\mathrm{rw}$ ). When the stock is close to 0 again for $r w$, then France is automatically considered.

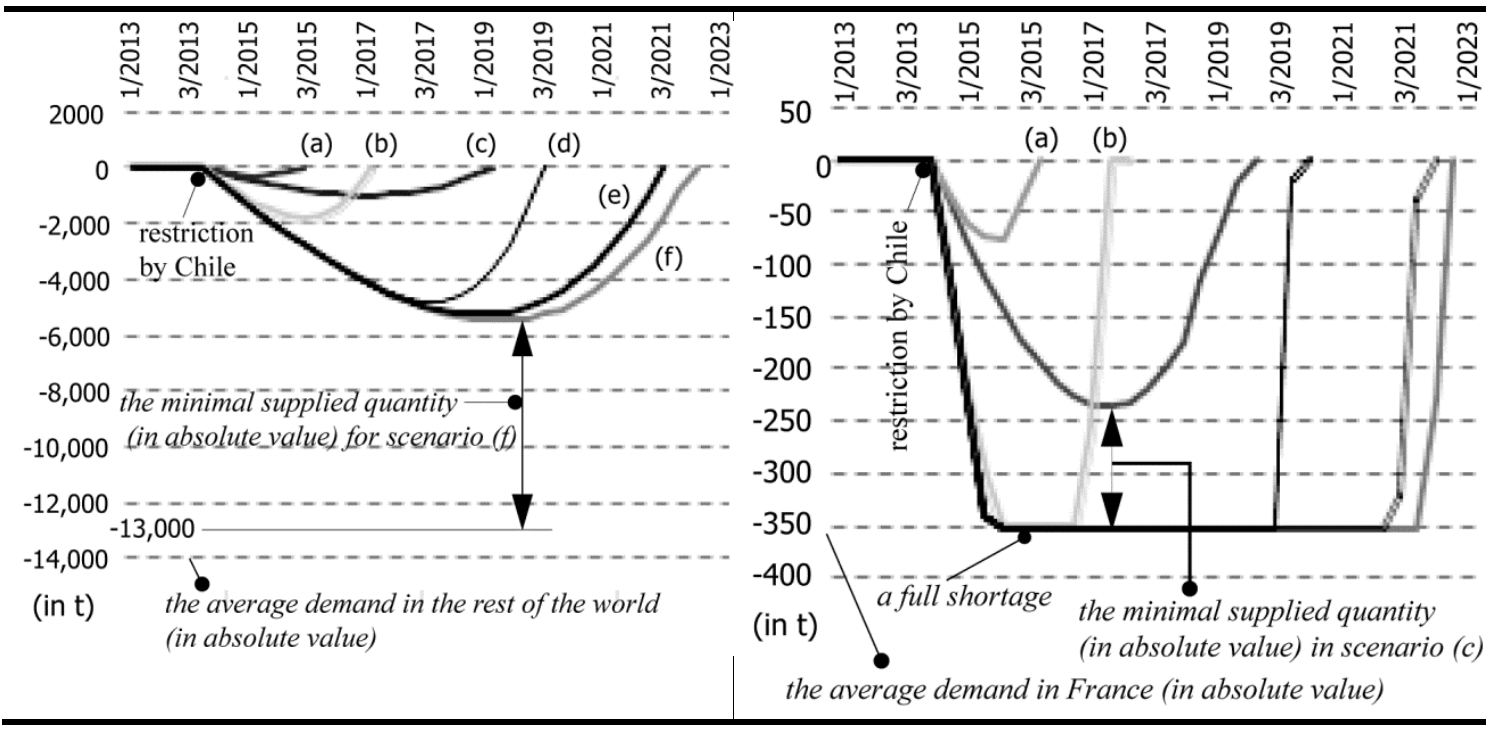

Figure 2.2: Prospective Evolution of the Lithium Stock in the Rest of the World (left) and in France (right), for all Scenarios

\subsubsection{Summary of the MAS reference model}

The MAS reference model is a purely bottom-up model i.e. it does not have any central mechanism to drive the interactions between producers and consumers. Furthermore, the maximum value of (year) 2023 mentioned in Figure 2.2 is not a time limit imposed by the model user, but an emergent result obtained during the simulation: it was observed that none of the periods of shortage exceeded this year. However, the model was designed, not as a substitution for classical statistical or mathematical approaches but rather as a complement (coupling) to them. Statistical approaches have been integrated to describe, not a global phenomenon, but the behavior of certain agents to which the approach is suitable. It particularly concerns the ambassadors. The linear regression tests were used with this objective. In the resulting system, certain agents behave in a linear manner (ambassadors and transit countries) while others (producing and consuming countries) adopt more complex and more discrete behaviors, which depend on their context.

\section{CRITIQUES OF THE MAS MODEL FROM MINING ECONOMISTS}

Relying on macro- and microeconomic reasoning and arguments, mining economists highlight various limits of the reference model when it has been confronted to "real world" situations. The corresponding critiques are categorized into four aspects: the data source, the structure, the behavior, and the simulation. They are detailed below and are followed by conclusions and indicators to improve the model performance. MAS responses to these critiques will next be provided in Section 4.

\subsection{Regarding the data source}

The data source GTIS (which originates from customs data) only contains flows between countries. It does not consider internal country consumption and production. In addition, there is a non-traceability issue. It means that if GTIS and more generally any customs data source like EUROSTATS, or USGS - the United States Geological Survey - are (relatively) accurate concerning the quantities of primary products ex- 
changed between countries, they do not trace the quantities of exchanged metals when they are already included in end-use products (e.g. quantities of lithium in traded cars). Non-traceability issues also means that for some metals (e.g. rare earths), there is a multiplicity of codes corresponding to different products containing the metal in its different forms. Table 3.1 gives an example of the issue in the data source (EUROSTAT, 2014) for rare earths. In this table, there are similarities between the products having different codes, making traceability difficult.

\begin{tabular}{l|l}
\hline HS code & Description in EUROSTAT \\
\hline 28053010 & $\begin{array}{l}\text { Intermixtures or interalloys of rare-earth metals, scandium and yttrium } \\
\text { Rare-earth metals, scandium and yttrium (Excl. intermixtures of interal- } \\
\text { loys) }\end{array}$ \\
280530901000 & $\begin{array}{l}\text { Cerium compounds } \\
\text { Compounds, inorganic or organic, of rare-earth metals, of yttrium or of } \\
\text { scandium or of mixtures of these metals (Excl. cerium) }\end{array}$ \\
\hline
\end{tabular}

Table 3.1: HS codes for raw rare earth product imports and exports (EUROSTAT, 2014)

\subsection{Regarding the simulation}

The time step chosen by the reference model is 3 months and the main agents are only countries. As the prospective exercise is on a long term $(\simeq 10$ to 15 years - cf. Figure 2.2), these choices seem to be correct.

However, it should be kept in mind that when the prospective exercise is on short $(\simeq 2$ to 5 years) to medium terms ( $\simeq 5$ to 10 years), these choices ( 3 month-time step, only country agents, etc.) are questionable. Indeed, at those scales, major industrial companies also have roles, particularly via the influences of their quarterly to bi-annual published results on daily and monthly evolutions in prices and exchanges. The example of the copper prices presented in Figure 3.1 indicates that their cycles are becoming tighter and tighter, requiring the simulation time step to be reduced accordingly. As metal market prospective studies may also cover short and medium-term scales, this aspect should be considered in future work when appropriate.

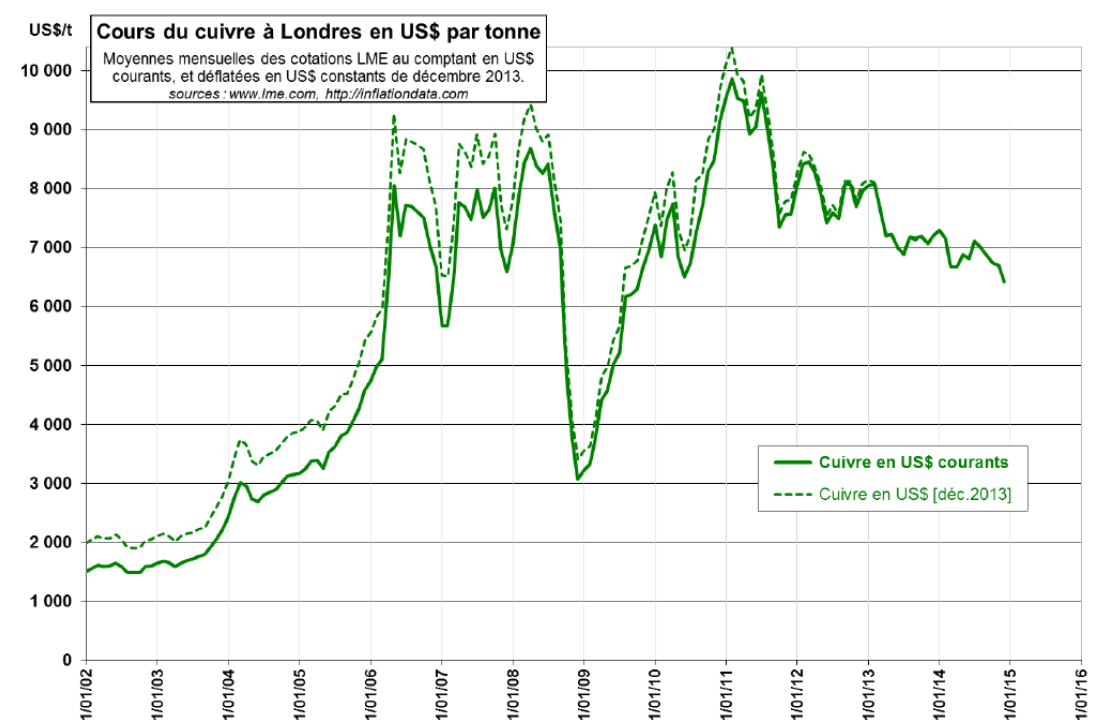

Figure 3.1: Variation of the copper price between 2002 and 2015 (BRGM, 2015) 


\subsection{Regarding the structural aspects}

The agents' structures lack properties which could influence greatly the outcomes. Indeed, the reasoning and equations only take quantities of "lithium carbonate" as the input variable while many other factors would need to be taken into account:

- in the 'ambassadors': price, geopolitical relations between countries, etc.

- in the '(producer) countries': costs of extraction and transformation (economic viability of the project), costs of transportation, etc.

- in the '(consumer) countries': internal demands, evolution of technologies

It is also noted that the model does not contain the secondary circuit at all. That would allow evaluation of the quantities of metals that can be obtained by recycling end-use products.

\subsection{Regarding the behavioral aspects}

\subsubsection{On the demand side}

The forecasting technique adopted by the demand model is based on extrapolation of historical data, resulting in the linear trends presented in Figure 2.2. Effectively, such an extrapolation technique was frequently used by the literature to analyze long-term metal market forecasts. We can cite, for instance, (Roberts, 2009) who analyzed the prices of 14 metals from January 1947 through December 2007, and (Shafiee \& Topal, 2010) who analyzed the prices of gold from January 1968 to December 2008.

Again, in conformity with comments regarding simulation time step (cf. Section 3.2), extrapolation may no longer be accurate to analyze medium-term trends of commodity prices and stocks. Indeed, there has been an important change in market fundamentals over at least the last two decades. Finance mechanisms have progressively been applied to commodity markets and have taken on non-negligible importance in their evolutions, introducing new key players such as banks and investment funds. In short, first order fundamentals (meaning global supply and demand, exchange rates, etc.) have become insufficient to represent the market structures and dynamics. There are now a number of second or third order parameters to take into account (speculative buyer behavior, shadow banking, resource nationalism, etc.). In addition, demand trends are becoming harder to forecast by relying on past data because, for most minor metals, they depend on the expansion of new promising technologies where they find their end use. All these situations also apply for short-term forecasting, where nonlinearity of economic data has already been admitted for decades (Agnon et al., 1999).

\subsubsection{On the supply side}

On supply side, the reference model put the strong hypothesis that when demand increases, producers can always increase their production capacity to respond accordingly. Unfortunately, the mining industry does not always allow such a mechanism. One of the best examples is rare earths: when China diminished its export by $40 \%$ in 2010, none of other producers could effectively compensate such a shortage even though other resources had been identified. The reason is that the industrial treatment facilities were not operational at that time. Currently, there are (non-exhaustive) factors that do not allow the above hypothesis to be realistic: availability of the resources, prices, political factors and internal demand of producing countries, which we explain below.

Availability of the resources: the strong hypothesis above primarily implies that the resource of compensating producers can compete in quality and price with the restrict- 
ing producer's resources. This parameter is far from obvious and raises the question: if other producers were able to supply more lithium before, why did not they do so? Most of the time, technical constraints explain this. These remain high barriers to alternative producers, who cannot modify their production instantaneously.

Prices: if the reaction of Chile restricting its lithium exportations could be a brutal evolution of lithium market prices, then other producers would also be affected by such a change and could also react by reducing their production voluntarily, awaiting better prices. Indeed, extraction cost is one of the main parameters in determining the rate of production of a mine so that only high enough metal prices can be a credible incentive to increase production (and only if technically feasible).

Political factors: related to the previous argument, price distortion raises the question of the possibility of "organized" market failures, such as monopolistic or oligopolistic situations, arrangements between producing countries, and free-rider issues. In such cases, price distortion could be advantageous for some producers and they would not take any measure to resolve the shortage issue quickly, similar to what OPEC members have done in oil price crises, for instance. The reference model tried to take this aspect into account by introducing a waiting step, allowing for a differed response from some countries, but the determinant of the corresponding variable is currently exogenous and set arbitrarily. Finding the determinants of this variable would be interesting.

Internal demand of producing countries: as producing countries usually import part of their supply from restricting producers (e.g. a large part of China and the USA's lithium also comes from Chile), those countries would also be affected in case of a uniform restriction (i.e. a restriction applied to all connected countries). Their eventual extra-production would then be used first for internal needs, rather than for international markets. Besides, since the chosen customs data (GTIS) do not take into account internal consumption (cf. Section 3.1), the supply value is not accurate.

\subsection{Conclusions from the economists}

MAS seems to be a promising approach to analyze metal markets. However, according to the mining economists, it is far from convincing for operational use. The reference multi-agent model described in this paper still needs a lot of refining to be able to describe market situations that are close to reality. In particular, the following questions are posed:

- How can the MAS approach reproduce high non-linear variations of metal market supply, demand and prices for the short or medium term, in an endogenous way?

- How can MAS integrate the complex characteristics of some metal markets (e.g. those involved in the exploitation of the 17 groups of rare earths)

- For which spatial and temporal scales is MAS modelling more appropriate? Can the approach handle multi-scale situations?

Nonetheless, through this work mining economists have provided a first category of metals that are more suitable for MAS modelling: base metals (copper, aluminum, iron, nickel, etc.), which are less critical than minor metals (antimony, indium, lithium, rare earths, etc.) (cf. Table 2.1 for these categories). The main reason for concluding this is data availability. In fact, in the metal market field, there is an inverse relation between data availability and its criticality. This is due at least to the following reasons: (a) the quantity of metals produced (a few or hundreds of tons for minor metals compared to millions or billions of tons for base metals) while some data sources 
ignore quantity below a threshold, (b) the way metals are traded as explained in Section 2.1.1 and (c) the speculation around their transformation into high value-added products

Regarding the non-traceability issue outlined in Section 3.1, to temporarily bypass this issue, the economists suggest that future ACE models should limit the number of enduses they manage while diversifying and cross-validating different sources of data (GTIS, EUROSTATS, USGS, Study Groups and Producer Associations, etc.). Limiting means avoiding (at least for the moment) simulating a primary product intended for too many industry end uses. This was what has been done in the reference model with lithium carbonate (mostly used for lithium-ion batteries) but the reasoning is valid for any metals. Obviously, this will not solve the non-traceability issue itself. This issue could be progressively resolved only if manufacturing producers would communicate more about the quantities of metals contained in their products. Meanwhile, this temporary solution will allow the progress in evaluating the MAS approach.

\subsection{Economists' suggestions for future work}

One suggestion from the economists to progress in evaluating the approach and the downstream modelling exercise is demonstrating MAS capacity via a showing-bydoing approach (Hamill, 2010). This would implement an ACE model which can reproduce the price behavior of some metals during a period containing the last crisis. The crisis scenario would be the following:

- an expected increase in demand of technologies which are dependent on a specific minor metal (cell phones with tantalum, new technologies with rare earths, etc.),

- "consumptionist euphoria" and a speculative bubble by the producers

- industrials and financial players building strategic stockpiles, reducing the available raw materials and leading to crazy price increases

- a sudden decrease in demand and consequently price.

Another suggestion for future models is to consider integrating other flow modeling techniques, including the modeling flow analysis (MFA) approach. This technique would be applied to analyze, for a given time/metal, how the input (instock, importation, production, etc.) evolves to output (consumption, outstock, exportation, etc.) for each country. This is important because in the current reference model, the flows circulating inside a country have been modeled in a 'simple' way: for example we cannot see (a) for a producer like USA, its importation, (b) for a consumer like France, its exportation, and (c) for transit like Belgium, a more precise analysis on which imported quantities are kept inside the country and which are exported to the final destination. MFA may be an interesting complementary approach to identify such lacks.

\section{DiscuSSION}

This section summarizes how the MAS modelers respond to the economic critiques from Section 3, with a view to taking them into consideration appropriately in future modeling work.

\subsection{Justification for using the MAS approach}

Before answering the critiques, it is worth recapping the interest of MAS especially for policy makers.

In fact, the debate on the methodological foundations of macroeconomic theory has gained new momentum during the recent worldwide economic crisis (Lengnick, 2013), a crisis where, in the metal market, an important supply shortage may be a fu- 
ture occurrence. Jean-Claude Trichet, the former President of the European Central Bank states the following (Trichet, 2010): “... As a policy-maker during the crisis, I found (...) in the face of the crisis, we felt abandoned by conventional tools (...). We need to deal better with heterogeneity across agents and the interaction among those heterogeneous agents (...) Such approaches are worthy of our attention..." That is why practitioners, governments and central banks are today very conscious that their understanding of the economic mechanisms has to be improved so that the linkages between various countries' (agents') systems at the international level can be demonstrated more explicitly, linkages which affect aggregate behavior (Kirman, 2011).

This necessity for scale change also applies to the particular case of metal supply shortage risk according to most of the studies measuring metal criticality gathered by (Speirs et al., 2013). In fact, those studies, although carried out at only aggregate level, are interesting for policy makers because (a) they are currently used operationally as a decision-aid model by industrialists, the European Union (EU), etc. and (b) they contain rich criticality determinants like geopolitical factors (governance, transparency, etc.), geological factors (substance availability, etc.), environmental factors, and economic factors (supply concentration, etc.). However, one limit of these studies is that they tried to assign a unique aggregated criticality score. Criticality differs from one country to another (depending for example on the geological reserves of the respective countries). The above authors then suggest future studies that would make the interaction between variables resulting in this unique score more explicit. Again, MAS is a solution. The idea is to design a 'country version' of these indicators inside an ACE model (cf. Section 4.3 for a first indicator).

In sum, we have here a research aspect (MAS) and an operational aspect (critical metals indicators at an aggregate level) that are currently attracting the attention of policy makers for analyzing metal criticality, especially as both aspects can be (theoretically at this stage) coupled inside one model.

\subsection{Regarding the comments from the economists}

Regarding simulation aspects (Section 3.2), comments related to the scale and complexity clearly demonstrate a lack of communication between the MAS field and the mining field concerning the foundation of MAS and its potential. MAS can simulate complex systems (Wooldridge, 2009) and can handle multiple time scales such as (if we take examples of ACE models) a day scale (Vriend, 2006), a month scale (Lengnick, 2013), a quarter scale (the reference model in this work), a year scale (Cheng et al., 2009), etc. MAS can also handle multiple space scales (if we look at the above work again): firm, household/country/world and can consider "financial agents" like banks (Tesfatsion, 2006).

Regarding behavioral aspects, the strong hypothesis (i.e. assuming that compensations of Chile's restriction by China and USA are always possible) noticed by the economists can be explained as follows: the current ACE work is one of pioneers in the mining field and is also a part of a methodological development in metal market forecasts. So (conceptually) assuming that when producer countries restrict, other countries compensate to maintain a market equilibrium is common sense. This could not simply be verified in the reference model because this model has missing parameters (cf. Section 3.2) and the corresponding missing behaviors. That said, these comments to avoid a strong hypothesis must be obviously integrated in future simulations to make the model realistic and usable at an operational level. 
Regarding structural aspects and the missing (economic, geopolitical and environmental) parameters in the reference model, there are no particular comments from the MAS modelers given that they are also aware of these lacks. Geopolitical variables will be integrated into our future work by relying on work concerning metal criticalities as outlined in Section 4.1. In fact, that work not only suggested what geopolitical variables to add to countries (e.g. governance indicators) but also indicated the corresponding data sources (World Bank, Transparency International, International Monetary Fund, etc.).

Regarding data issues and particularly the non-traceability issue, the MAS field cannot solve this alone. At this time MAS will follow the recommendations from the economists (cf. Section 3.5): (a) simulating one specific product intended to one specific industry end-use while (b) diversifying and cross-validating different data sources (GTIS, OECD, EUROSTATS, USGS, etc.).

Regarding the economists' expectation of introducing MFA, the comments clearly highlight the wish to reinforce the coupling of classical and MAS approaches in the modeling of metal markets instead of sticking to a solely MAS approach. This means MAS should be considered as a complementary approach rather than a substitute for the classical approach. The reference model had already started to consider this idea (i.e. coupling MAS and statistical approaches - cf. Section 2.2.5). But for future model developments, it could be further enhanced by henceforth methodologically extending the coupling to the other approaches. Concretely, these approaches are (a) material flow analysis, (b) work on metal criticalities mentioned above (which integrate geopolitical variables), (c) spatialization processes via geological maps and country maps (which consider geological variables and transport distances respectively) and (d) metal life-cycle analysis (LCA). Metal LCA (Nuss \& Eckelman, 2014) will be introduced in future ACE work to evaluate the environmental impact of metal exploitation as recommended by the EU (EU, 2011) but in this case, inside a MAS simulation. This coupling to LCA can be carried out by considering environmental properties (energy end-use, global warming potential, human health implications and ecosystem damage) in agents' properties and how they are manipulated in agents' behaviors (mining, transport, transformation, recycling, etc.).

Throughout these actions, the MAS modelers are aware that it is incumbent on MAS simulation, for better acceptance of its usefulness, to justify its added value in enriching existing methodologies regarding metal market analysis, not the opposite.

\subsection{How to create the showing-by-doing demonstration}

This section explains how the MAS modelers plan to actualize the showing-by-doing demonstration requested by the mining economists, i.e. reproducing some metal price behavior covering periods of the last crisis (cf. Section 3.6).

\subsubsection{The metal}

Simulating rare earth markets and its 17 groups of elements, as expressed by the mining economists in Section 3.5, is too premature at this stage although more interesting (because critical) and conceptually possible via MAS approach. The chosen metal for that demonstration will be copper. Since this is a medium-term simulation, the exercise will be carried out at a month-time step (not the quarter-time step adopted by the reference model) and with the idea of reproducing high price variations (cf. Figure 3.1 ) and demand in an endogenous way. 
Copper is chosen for the following reasons and more:

- Copper's economic data (price, quantity) are more available than data on lithium or rare earths, not only for import-export flow but also for production and consummation inside a country (see Section 3.5 for the explanation). This is true for all primary or secondary (recycling) circuits of this metal (via GTIS, EUROSTAT, IMF, etc.) but also for environmental evaluation (the Eco-invent database).

- Copper end-use is, at more than $50 \%$ of market share, intended for the construction and automotive sectors where data is more available than for some other metal end-uses. For a modelling exercise, these data (sharing more than $50 \%$ of enduse market) are not negligible so they diminish the effect of the non-traceability issue.

- We could refer to recent studies on the criticality of copper (i.e. including geopolitical aspects) (Nassar et al., 2011).

\subsubsection{Baseline of the future ACE model}

Regarding the future copper ACE model, the following baseline indicators are suggested.

The design of links between producers and consumers would be modeled by direct sequences of ask-bid processes between producers and consumers according to their local knowledge of the market. The future work would then keep the fully bottom-up approach adopted by the reference model (cf. Section 2.2.5) while avoiding the extrapolation process limiting that model as argued in Section 3.4.1. The future work would also rely on the work of (Cheng et al., 2009). That is interesting because (a) it considers additional market agents (hedgers, traders, etc.), (b) during an ongoing simulation, it considers different market external events that drive complicated price movement with only simple agent strategies and (c) it has been applied to the simulation of world crude oil price evolution, theoretically facilitating its transposition to our copper trading market. Figure 4.1 shows an example of the efficiency of such a model, in particular the ability of one agent trader to progressively comply with the trend indicated by real-world market price.

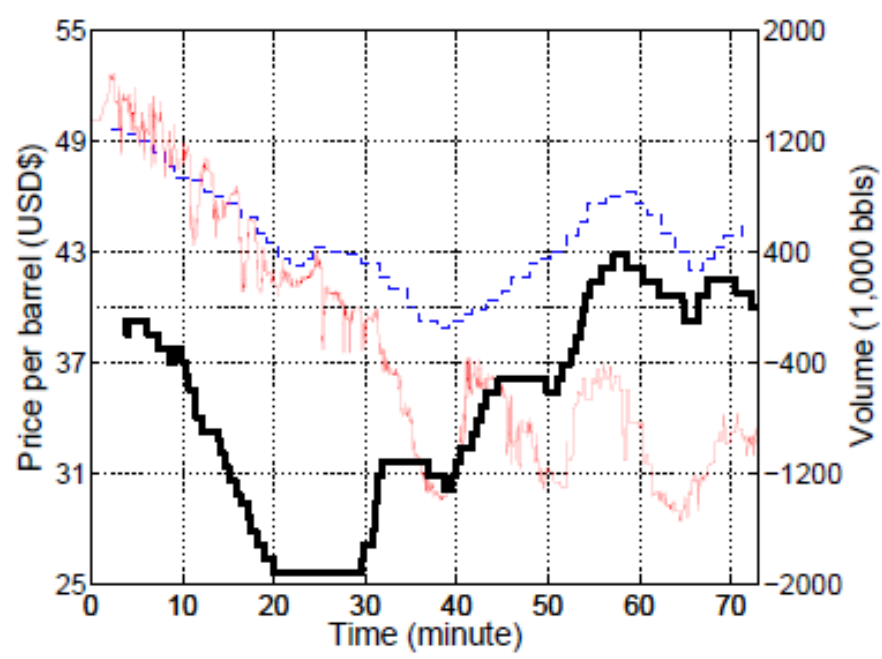

Figure 4.1: Example of a trader agent behavior (Cheng et al., 2009):

thick line is trader's position balance; thin line is real market price; dotted line is estimated market price dynamics 
Regarding the evaluation of the demand in that future work (mostly in the construction and automotive sectors, as mentioned previously), it would rely on the ACE work of (Lengnick, 2013). That work is a fully bottom-up market model that computed agents' demands according the household needs (i.e. a variable from which construction and automotive needs could also be computed).

\subsection{Regarding the future of MAS acceptance}

It seems to be clear that MAS is a promising tool for prospective simulation of metal markets, among other reasons because it would be of interest for a policy maker (Section 4.1) in market analysis after the recent economic crisis. MAS is also open enough to be theoretically coupled with more classical existing approaches (Section 4.2). However, while the intention behind these MAS responses is to conform as close as possible to mining economists' suggestion, success will be defined by the economists accepting MAS and is far from obvious for at least two reasons: data obstacles and paradigm obstacles.

\subsubsection{A data obstacle}

As demonstrated in the entire paper, the data available in metal markets are not 'ready' yet for MAS simulation. One reason is because the industrial metals market at an international scale has never considered the necessity of constructing and organizing data for a simulation purpose. In addition, at more detailed levels, data are confidential to varying degrees, published according to criteria variable from one country to another (the metal, the producing company, the country, etc.). Consequently, although rare earths would be the next metal whose market is interesting to simulate for the showing-by-doing MAS demonstration suggested by the economists (i.e. the capability for simulating the last crisis), copper was finally chosen not because it is the most critical metal but because its market has one of the best quantities of available data. It is hoped that once a future copper model is implemented and validated, the resulting work would incite the mining field to progressive collection and validation of raw material data at the international level for a simulation purpose. The mediumterm idea is to concretely succeed in creating a cyclic process between (a) increased successful transpositions of the reference model, (b) better organization and reliability of data (c) better acceptance of the underlying method, (d) progression in the demand of MAS approach for studies from different entities (consultants, scientists, etc.) at an operational level. Such a cyclic process already exists and is recognized at an operational level but only for a global level, not at an international level.

\subsubsection{A paradigm obstacle}

Even though it is assumed the showing-by-doing test expected by economists would produce interesting results, we detected many sources of reluctance in using the approach. First, we recognize that from the economist's viewpoint, agent-based modelling has an obvious drawback: it makes it impossible to think in aggregate terms. Multi-agent modelling also has a destructive consequence: the dimension of the model explodes (Assenza \& Delli Gatti, 2013). Second, a MAS is composed of autonomous agents and emergent phenomena while mining economists would like to "keep control" of their analysis, i.e. not letting computers reason in lieu of them. Third, how long it will take to design one application scenario is not clear and during a simulation, the time each agent will take (in real time) to behave is not clear either. There is an uncertainty on how many times, at the most, such potential users should wait before obtaining one scenario result (at a scale of a minute? a week?). All of these 
sources of reluctance are unlikely to disappear in the short term but we should at least constantly highlight them in future MAS research papers concerning progress towards better acceptance of the MAS method in the metals field.

\section{CONCLUSIONS}

In coming years, mining economists expect the international demand for metals to rise. Market distortions are likely to appear because producing countries controlling the resources can implement exportation quotas for certain categories of metals, for political or environmental reasons. Consequently, consuming countries like France are facing increasing risks of shortages for some metals. In response to that, the French government suggests the implementation of a set of prospective tools among which is a prospective simulation tool based on a multi-agent system approach. The goal of this paper was to report and discuss critiques carried out by the economists regarding the value of and ability of a multi-agent system to simulate critical metal markets whenever the approach is appropriate. The critiques were collected by comparing an existing agent-based computational economics (ACE) model of the lithium market to market reality and by generalizing the discussions to other metals. The motivation is (a) to define the gaps currently existing between MAS and mining economists (b) to provide indicators on how the ACE model should be enhanced in the future to reduce these gaps and (c) in parallel, to produce an improved initial metal classification that is suitable for such a modelling exercise. We can summarize the results as follows.

First, finance mechanisms have progressively taken on non-negligible importance in the evolution of macroeconomics (and even more so metal markets, a field of macroeconomics), introducing new key players such as banks and investment funds. Practitioners, governments and central banks are today very conscious that knowledge of the economic mechanisms has to be improved so that the network structure of the financial industry can be more explicitly demonstrated at an international level, a structure which next has an important impact on aggregate behavior. Consequently, unlike what is proposed by the reference model, prospective modeling of metal market demand by only extrapolating its historical data will be less and less appropriate. Trends are becoming harder to forecast by relying on past data because, for most of the minor metals, they depend on the expansion of new promising technologies in which they are used, which could eventually be replaced by even newer technologies in a decadelong period. In sum, demand and price variation will be more and more non-linear and the prospective modeling technique should be improved to better identify the determinants of that evolution.

Second, a Multi-Agent System approach and more specifically, for this work, AgentBased Computational Economics (ACE) models, is conceptually recognized as appropriate for simulating the complex metal market as described above. The recognition comes from scientists but also from policy makers, especially after the recent economic crisis. Nonetheless, we also recognize that there is a lack of communication to mining economists regarding the MAS foundation and potential for simulating such a market. Thus, for progress towards a better acceptance of MAS by the economists:

- mining economists expect demonstration by a showing-doing-approach, in particular an ACE model which would be capable of reproducing high price and demand variation of for a metal during a period including the recent crisis, in an endogenous way. Copper will be chosen for that demonstration.

- classical modeling approaches should be more and more highlighted in the model as far as appropriate, instead of a solely MAS structure. 
Third, available data in metal markets are not 'ready' yet for MAS simulation. Consequently, although rare earths would be the next metal whose market was interesting to simulate, copper has been chosen not because it is the most critical metal but because its market has one of the best quantities of available data. More generally, this work has allowed mining economists to provide a first category of metals that are more suitable for a MAS modelling: base metals (copper, aluminum, iron, nickel, etc.) rather than minor metals (antimony, indium, lithium, rare earths, etc.). It is hoped that once a future copper model is implemented and validated, the resulting work would incite the mining field to progressively collect and validate more critical metal data at the international level for a simulation purpose.

Finally, we recognize that even though it is assumed that the showing-by-doing test expected by mining economists would produce interesting results, they will still be reluctant to adopt the MAS approach as a tool at the operational level, at least in the short term, among other reasons because (a) they are used to keeping control of their analysis, while MAS provides autonomous agents and emergent mechanisms and (b) MAS currently contains a level of complexity that is not still suitable for them in terms of model and simulation designs. These sources of reluctance will not immediately disappear but we should constantly highlight them in future MAS research papers to aid progress towards better acceptance of the MAS method in any application.

In terms of perspectives for the present work, the next step is to achieve the showingby-doing demonstration. We plan to base that work on ACE models already existing in the literature (Cheng et al., 2009; Lengnick, 2013).

\section{REFERENCES}

Agnon, Y., Golan, A. \& Shearer, M., 1999. Nonparametric, nonlinear, short-term forecasting: theory and evidence for nonlinearities in the commodity markets. Economics Letters, 65, pp.293-99.

Andriamasinoro, F. \& Martel-Jantin, B., 2013. Proposal of agent simulation methodology for the prospective analysis of mineral commodities markets. In Affenzeller, M. et al., eds. The 12th International Conference on Modeling and Applied Simulation. Athens, 2013. Rende (CS), Italy. 25 - 27 September.

Assenza, T. \& Delli Gatti, D., 2013. E Pluribus Unum: Macroeconomic modelling for multi-agent economies. Journal of Economic Dynamics \& Control, 37, pp.1659-82.

BRGM, 2015. Évolution des prix de divers métaux et autres substances minérales entre janvier 2002 et 2014. [Online] Available at: http://www.mineralinfo.fr/ecomine/evolution-prix-divers-metaux-2002-0.

Cheng, S.-F., Lim, Y.P. \& Liu, C.-C., 2009. An agent-based commodity trading simulation. In The 8th International Conference on Autonomous Agents and Multiagent Systems. Budapest, 2009. May 10-15.

EU, 2011. Opinion of the European Economic and Social Committee on the 'Access to secondary raw materials. CCMI/078. European Commission.

EUROSTAT, 2014. Your key to European statistics. [Online] Available at: http://epp.eurostat.ec.europa.eu. European Commission.

Graedel, T.E. et al., 2012. Methodology of Metal Criticality Determination. Environmental Science \& Technology, 46(2), pp.1063-70. 
GTIS, 2012. Online market database. [Online] Available at: https://www.gtis.com/gta/ [Accessed 2014].

Hamill, L., 2010. Agent-based modelling: the next 15 years. Journal of Artificial Societies and Social Simulation, 13(4). http://jasss.soc.surrey.ac.uk/13/4/7.html.

Kirman, A., 2011. The Crisis in Economic Theory. Rivista italiana degli economisti, 16, pp.9-36.

Kushnir, D. \& Sandén, B.A., 2012. The time dimension and lithium resource constraints for electric vehicles. Resources Policy, 37(1), pp.93-103.

Labys, W.C., 2003. New Directions in the Modeling and Forecasting of Commodity Markets. Mondes en développement, February. pp.3-19.

Lengnick, M., 2013. Agent-based macroeconomics: A baseline model. Journal of Economic Behavior \& Organization, 86, pp.102-20.

Nassar, N.T. et al., 2011. Criticality of the Geological Copper Family. Environmental Science \& Technology, 46(2), pp.1071-78.

Nuss, P. \& Eckelman, M.J., 2014. Life Cycle Assessment of Metals: A Scientific Synthesis. PLoS ONE, 9(10).

Roberts, M.C., 2009. Duration and characteristics of metal price cycles. Resources Policy, 34, pp.87-102.

Roskill, 2011. Rare Earths \& Yttrium: Market Outlook to 2015.

Shafiee, S. \& Topal, E., 2010. An overview of global gold market and gold price forecasting. Resources Policy, 35, pp.178-89.

Soulié, J.-C. \& Thébaud, O., 2006. Modeling fleet response in regulated fisheries: an agent-based approach. Journal of Mathematical and Computer Modelling. Elsevier, 44(5-6), pp.553-64.

Speirs, J., Houari, Y. \& Gross, R., 2013. Materials Availability, Working paper III: Comparison of material criticality studies - methodologies and results. UKERC Report UKERC/WP/TPA/2013/002.

Tesfatsion, L., 2006. Agent-based computational economics: A constructive approach to economic theory. In L. Tesfatsion \& K. Judd, eds. Handbook of Computational Economics. Elsevier. Ch. 16. pp.831-80.

Torii, D., Ishida, T. \& Bousquet, F., 2006. Modeling agents and interactions in agricultural economics. In The 5th international joint conference on Autonomous agents and multiagent systems. Hakodate, 2006. AAMAS, ACM New York.

Trichet, J.-C., 2010. Reflections on the nature of monetary policy non-standard. In Speech by the former President of the ECB, Opening address at the ECB Central Banking Conference. Frankfurt, 2010. 18 November.

Tru, 2011. Shocking Future Battering the Lithium Industry through 2020. In the 3rd Lithium Supply \& Markets Conference. Toronto, 2011. LSM. January 19 - 21.

Van Pruissen, O., Van der Togt, A. \& Werkmana, E., 2014. Energy Efficiency Comparison of a Centralized and a Multi-agent Market Based Heating System in a Field Test. In Robert $\mathrm{J}$ Howlett, ed. The 6th International Conference on Sustainability in Energy and Buildings, SEB-14. Cardiff, Wales, UK, 2014. Energy Procedia. 25 - 27 June 2014. 
Vriend, N.J., 2006. ACE models of endogenous interactions. In L. Tesfatsion \& K. Judd, eds. Handbook of Computational Economics. Elsevier. Ch. 21. pp.1048-78.

Wooldridge, M., 2009. An Introduction To Multiagent Systems. 2nd ed. John Wiley \& Sons. 499 p. 